\title{
An Analysis of Uniqlo's Management Philosophy and Its Enlightenment to China's Fast Fashion Brands
}

\author{
Ningbo Wang, Chenggang Li \\ Business School, Beijing Institute of Fashion Technology, Beijing, China \\ Email: 18612806135@163.com
}

How to cite this paper: Wang, N.B. and $\mathrm{Li}$, C.G. (2018) An Analysis of Uniqlo's Management Philosophy and Its Enlightenment to China's Fast Fashion Brands. Open Journal of Social Sciences, 6, 301-308. https://doi.org/10.4236/jss.2018.63022

Received: March 26, 2018

Accepted: April 6, 2018

Published: April 9, 2018

\begin{abstract}
This article mainly studies the internationalization process of the Uniqlo, a fast-fashion brand of Japan Fast Retailing Group, and summarizes its successful experience in product positioning, strategic positioning, SPA business model, and Internet plus marketing and etc, at the same time, it analyses the weaknesses of Chinese fast fashion brands. In order to improve their international competitiveness, these brands must do the following: attaching importance to product R \& D and design, strictly controlling product quality, strengthening self-brand building, improving supply chain management system, expanding sales channels and establishing Customer Service Center and so on.
\end{abstract}

\section{Keywords}

Strategic Positioning, SPA Business Model, R \& D and Design, Brand Building, Customer Service Center

\section{Introduction}

In 1984, when the Japanese economy was in recession, the first Uniqlo store opened in Hiroshima, Japan. In 2001, Uniqlo saw the market opportunities brought by China's accession to the World Trade Organization, and it ventured into the Chinese mainland market. However, due to its strategic mistakes, the company suffered a great loss in the Chinese market. For a long time since then, Uniqlo has been very quiet. Until 2009, Uniqlo opened its TMALL flagship store, at that time, Uniqlo Drew the attention of Chinese consumers once again.

So far, Uniqlo has nearly 1030 direct-operated stores around the world. Its latest financial report shows that sales from September 2016 to August 2017 were approximately RMB 109.259 billion, and its net profit was approximately 
RMB 20.5 billion. Both sales and net profit reached the highest level in its history. When Uniqlo was founded, it was the time when Japan's economy was in a recession. Success seemed to be a luxury for most startups. However, Uniqlo has taken its own path to success by virtue of its unique operation. Uniqlo's business philosophy is worth learning for Chinese fast fashion companies.

\section{Strategic Positioning}

In the choice of international business strategy, Uniqlo followed closely the strategy of large-scale multinationals' combination strategy, which took globalization strategy as the key link and localization strategy as a supplement, it not only makes up for the defects of the globalization strategy, but also meets the differentiation needs of localization strategy[1].

\subsection{Globalization Strategy}

The typical feature of the globalization strategy is that product R \& D is carried out in the home country, and production and sales are implemented in the host country. The mother country company strictly controls product development, design, production, logistics and sales. The obvious advantage of the globalization strategy is that it helps to control and save costs. The disadvantage is that the degree of global product collaboration is lower and the market adapting capacity of the host country is poorer.

\subsubsection{Globalization of Procurement}

With low-cost competitive advantages, UNIQLO has opened its most directoperated stores in the bustling business district of the city to increase its brand awareness. The cost of raw materials strictly determines the cost of the product. Uniqlo procured the raw materials it needs on a global scale, and established a long-term cooperative relationship with suppliers, so it can obtain more advantageous raw material purchase prices.

\subsubsection{Globalization of Production}

Prior to this, Uniqlo placed more than $90 \%$ of its productive activities in Chinese Mainland, but with the continuous increase of labor cost in China in recent years, Uniqlo has expanded its production activities to countries such as Vietnam, the Philippines, and Bangladesh, because these countries have cheaper labor force and more abundant raw materials than that in China.

\subsubsection{Globalization of Market}

Currently, there are 1029 Uniqlo direct-operated stores all over the world, they are located in major markets in most countries in the world. About $70 \%$ of Uniqlo's apparel are basic styles, these basic styles can be standardized- production globally, so the economies of scale can be achieved easily.

\subsection{Localization Strategy}

Under localization strategy, each host country's subsidiary has a greater opera- 
tional decision-making authority. Subsidiaries can produce different products and formulate diversified marketing strategies according to the special needs of local consumers to meet the individualization demands of different markets. The localization strategy has a stronger ability to adapt to the target market, and it also has a faster market response. At the same time, the localization strategy has its defects, such as relatively high production and marketing costs, and over-independence of each subsidiary. So, the cooperation among the subsidiaries is slightly worse.

\subsubsection{Localization of Product}

In addition to $70 \%$ of the basic styles, UNIQLO has also developed and designed differentiated products to adapt to the local culture and customs of the host country. For example, the "3-D fit" products that offered in Europe and the United States are designed to meet local obese people's clothing needs.

\subsubsection{Localization of Pricing}

It is the primary task of UNIQLO's internationalization process that global consumers can afford its products. In addition to the basic models, its personalized products are basically differentiated pricing, for example, UNIQLO provides better-quality and higher-price products in US, but in Asian countries, especially in Southeast Asia, UNIQLO maybe omit some seemingly insignificant designs to provide cheaper products while ensuring the quality of its products.

\subsubsection{Localization of R \& D Center}

Currently, Uniqlo has Japan, New York, and Paris R \& D centers to meet local needs for differentiation. The $\mathrm{R} \& \mathrm{D}$ center in Japan mainly serves some Asian countries such as China, Japan, South Korea, and Southeast Asia countries; the New York R \& D center serves culture-similar North American countries, such as the United States and Canada; and the Paris R \& D center mainly provide services for the European markets.

\section{Product Positioning}

Unlike H \& M, GAP, and other fashion brands, Uniqlo pays more attention to the "basic portion" that accounts for $70 \%$ of its total clothing. At the same time, it incorporates some fashionable and popular elements of the season to make its products more avant-garde and fashionable.

\subsection{Fashion \& Joker}

In order to make its garments fit freely with most garments and most people, Uniqlo designs $70 \%$ of its garments as the basic styles, and it also incorporates some fashionable and popular elements of the season accordingly, which leads its products more avant-garde and stylish.

\subsection{Good \& Inexpensive}

Another important feature of UNIQLO is its high quality and inexpensive. To 
provide global consumers with high quality and functional products, Uniqlo sent experts to the factory for technical guidance and supervision, and tracked product development, design and production, they strictly implemented the three standards of quality management system: emphasis on the quality of partnership, business process quality and social quality [2] (Figure 1).

\subsection{Wide Consumer Groups}

Uniqlo's consumer groups are very wide, ranging from students, young people to middle-aged people, and even senior citizens, its products covered 9-60-yearold consumer groups. Such a wide consumer group has enabled Uniqlo gain more markets shares and competitive advantages.

\section{SPA Business Model}

In 1998, after Uniqlo completed its $\mathrm{ABC}$ reform, it gradually began to adopt its unique SPA business model. SPA is a vertically integrated business model that integrates product development, design, manufacturing, logistics and sales together. The SPA model has the following advantages.

\subsection{Price Advantage}

Different from the traditional clothing industry's business model, Uniqlo abandoned the existence of middlemen, so it saved the cost of middlemen and further improved the price competitive advantages.

\subsection{Channel Control}

Foxconn has become very dependent on Apple Inc for its agency production, Uniqlo is no exception, because Uniqlo is directly involved in the management of its direct-stores, the company's demand for products is very large, the large

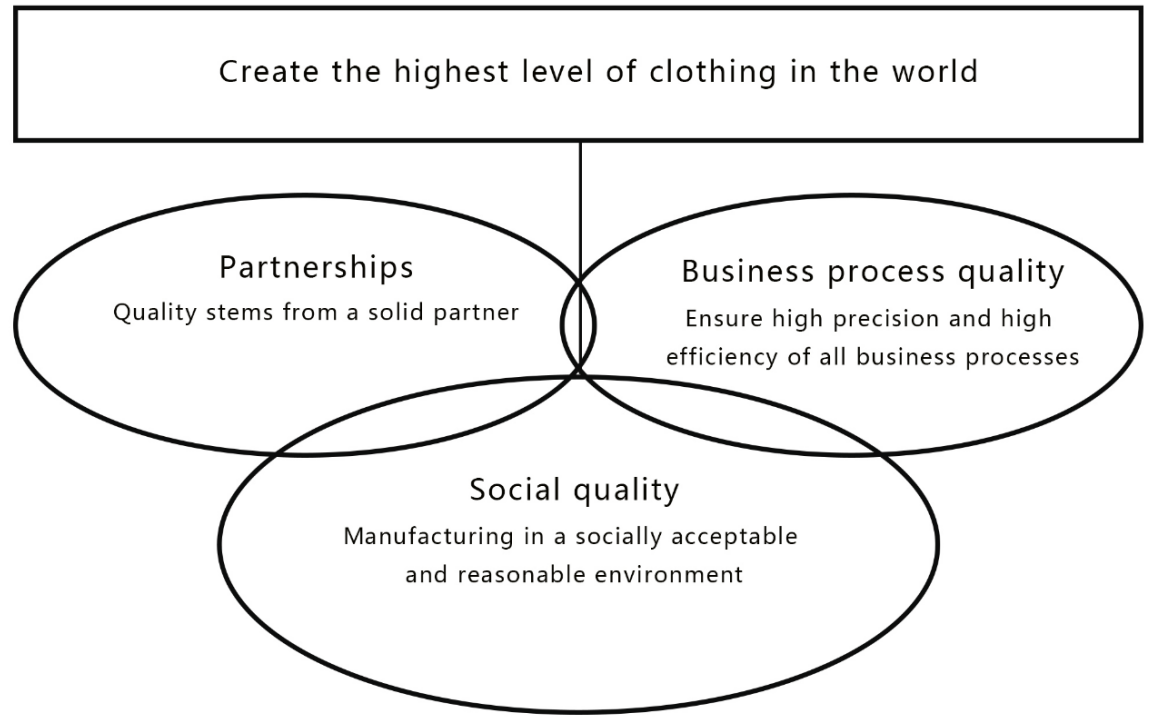

Figure 1. The three standards of quality management system. 
demands makes the agent factory further rely on Uniqlo. In this way, Uniqlo can better control its sales channels to ensure its product quality and delivery time.

\subsection{Access to Information}

Uniqlo has accumulated plenty of operating data of each direct-store, since it directly participates in the operating management of various direct-stores. Through the analysis of these data, it is possible to more accurately understand the shopping behavior of consumers and predict future sales trends. Furthermore, it also helps to formulate more effective production and marketing strategies.

The success of Uniqlo was not a chance, it is just because Uniqlo adopted the SPA business model and established its own strong supply chain management system, which spurred Uniqlo gained a competitive advantage in essence. Through the improvement of the traditional supply chain model in the past, Uniqlo has realized that "Marginal Technology Line A" shifted to the right curve(Marginal Technical Line B) (Figure 2). Compared to traditional apparel companies, Uniqlo achieved the same service at a lower price, and even a better service [3].

\section{Internet plus Marketing}

Since Uniqlo opened its online flagship store in 2009, its network sales and net profit have grown significantly year after year, and it also has become the leader of Tmall flagship apparel companies. In Tmall double 11 of 2017, night zero just over 1 minutes, Uniqlo network sales exceeded one hundred million yuan, after

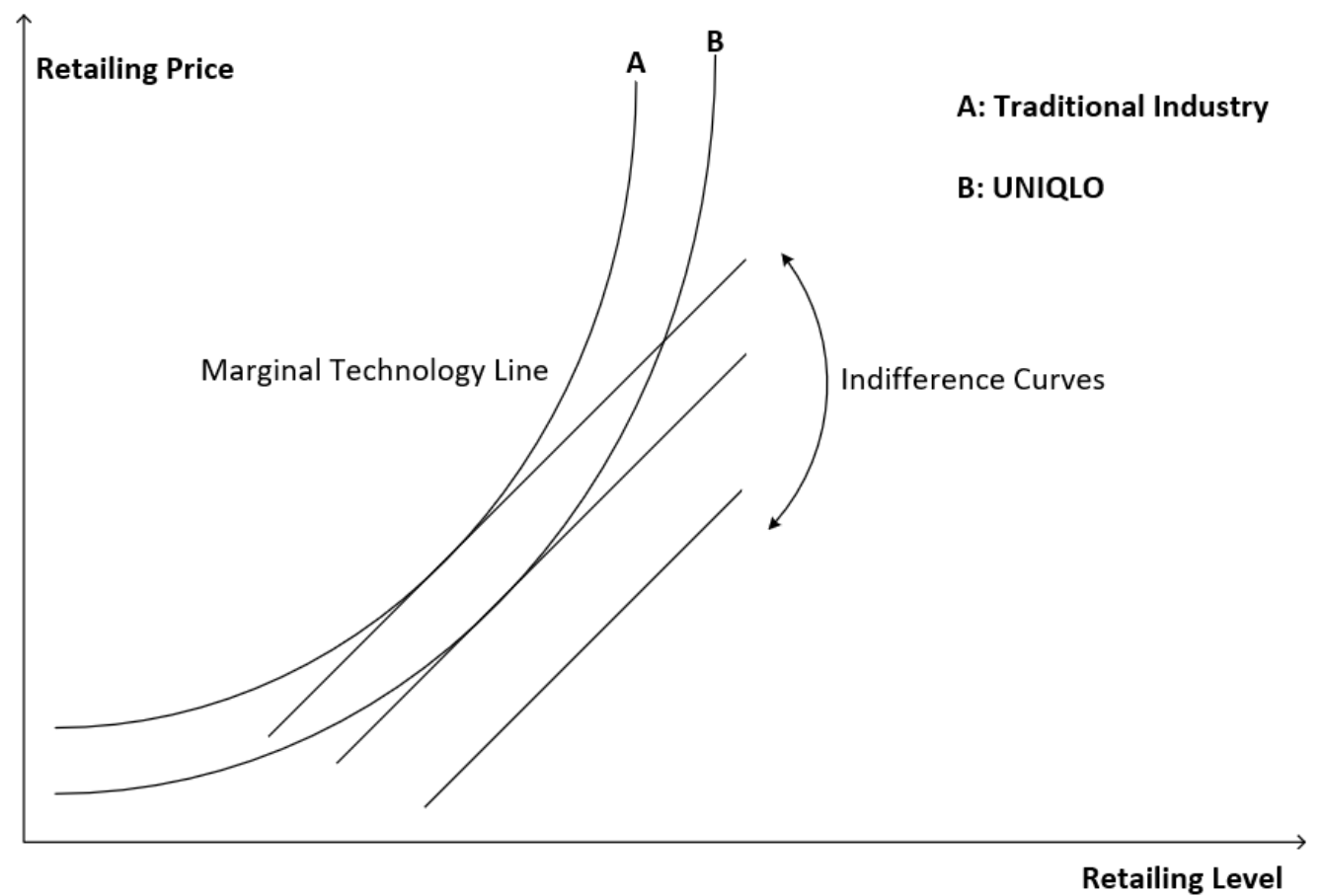

Figure 2. The comparison of technical boundary lines. 
the day, it is no doubt that Tmall won the clothing class champion.

Although Uniqlo's online sales model has achieved great success, Uniqlo didn't confined itself to online sales. Instead, it used a variety of marketing means to enhance its brand effect. At present, the number of fans of the Uniqlo official WeChat public account has exceeded 15 million, through Brand Story, Customer Voice, Design Philosophy, Trend Arrangement, and Fun Interactive modules designs, Uniqlo achieved more interaction with users, fully mining of user value, enhancement of user experience, increasing of user stickiness and more fans, which brings more stable customer traffics for its physical stores. UNIQLO is also actively implementing a new product model that changes from "Made For All" to "Made For You" [4]. In addition, Uniqlo used artificial intelligence to build a global customer digital information platform (New Retailing Model), which subverted traditional online retailing and pure entity retailing in the past.

\section{Inspirations of Domestic Fast Fashion Brand}

\subsection{Pay Attention to Product R \& D and Design}

China's fast-fashion brands have been a labor-intensive industry for a long time, and its designs also lack innovation seriously. Because of inadequate R \& D and backward designs, which has led to China's first- and second-tier fast fashion markets being occupied by foreign fast fashion brands. China's fast fashion brands can only go to third and fourth-tier cities to seek market shares. If things go on like this, it will just increase the distance between itself and the international fast fashion brands. In the future, the development of international apparel fabrics will be green, environmentally friendly, comfortable and functional, and the future apparel design will be more diversified, therefore, china's fast fashion brands should pay more attention to product R \& D and design, while they focus on developing their competitive fabrics, they can also design a futureoriented and leading products.

\subsection{Emphasis on Product Quality}

It is just because Uniqlo established a team of experts to enter the factory for technical guidance and product testing that Uniqlo's brand images have changed from low-price clothing to a high-quality fast fashion brand. Quality is the core of products, ensuring product quality is the base of product internationalization. China's fast fashion brands should stay in step with Uniqlo and formulate strict product quality standards, only when the quality of the product reaches the standards, can they bypass the international trade barriers and enter the international markets to participate in the international competition.

\subsection{Focus on Brand Building}

The domestic fast fashion brand's product positioning and market positioning are vague and they always imitated each other. The worst thing is that the brand 
maintenance is not in place, which caused the brand images to be damaged. China's fast fashion brands should respond to the call of "National Brand Strategy", do well in brand building and maintenance, and establish brand image and connotation in the minds of consumers, so that consumers can truly feel the added value brought by brand effect.

\subsection{Improve Supply Chain Management System}

"Lead time" refers to the time required from product design to sale. The "Lead Time" for domestic fast fashion brands is generally 3 - 6 months, while the fastest time for international fast fashion brands can reach one month. The domestic fast fashion brands not only have a long production cycle, but have a low reaction to the market. Uniqlo relied on its unique SPA business model to collect and control market information independently, make plans based on market demand, and quickly complete a series of work, such as product design, raw material procurement, production, logistics distribution, and marketing. Domestic fast fashion brands should learn from Uniqlo's SPA business model and establish their own efficient supply chain management system to shorten their product production cycle and speed up their response to the market.

\subsection{Broaden Sales Channels}

Although domestic fast-fashion brands are also trying online marketing, they still have a big gap with Uniqlo's internet marketing. China's fast fashion brands should actively develop network marketing and change their traditional modes of thinking.

\subsection{Establish Customer Service Center}

In order to produce products that satisfied consumers, domestic fast fashion brands must listen to the opinions of consumers. Uniqlo continuously improves product quality and its customer service levels according to the opinions and suggestions from the customers, finally, Uniqlo won the brand value effect so high today. Therefore, the domestic fast fashion brand should also do well in aftersales service of the products, seriously listen to the customers' suggestions, and further improve the product quality and product service.

\section{Conclusion}

Fast fashion brands, as an important part of China's apparel industry, should actively implement a series of transformational measures under the call of the "Belt and Road" national strategy. For example: emphasising on product R \& D and design, strictly controlling of product quality, strengthen the construction of brand, improving the supply chain management system, expanding sales channels and setting up customer service centers, etc, at the same time, they should actively explored the strategy of "going out" so as to participate in the allocation and sharing of global resources. 


\section{Acknowledgements}

I would like to thank all the people who participated in the writing of this paper, and a special thanks to professor Chenggang $\mathrm{Li}$ for his tireless guidance and support.

\section{References}

[1] Caro, F. and Gallien, J. (2010) Inventory Management of a Fast-Fashion Retail Network. Operations Research, 58, 257-273.

[2] Jung, J. and Shen, D. (2011) Brand Equity of Luxury Fashion Brands Among Chinese and U.S. Young Female Consumers. Journal of East-West Business, 17, 48-69. https://doi.org/10.1080/10669868.2011.598756

[3] Tokatli, N., Wrigley, N. and Kizilgün, Ö. (2008) Shifting Global Supply Networks and Fast Fashion: Made in Turkey for Marks \& Spencer. Global Networks, 8, 261-280.

[4] Tong, X. and Hawley, J.M. (2009) Measuring Customer-Based Brand Equity: Empirical Evidence from the Sportswear Market in China. Journal of Product \& Brand Management, 18, No. 4. 